Sharif University of Technology
Scientia Iranica
Transactions E: Industrial Engineering
hCIENTIA

\title{
Chance-constrained programming and robust optimization approaches for uncertain hub location problems in a cooperative competitive environment
}

\author{
F. Nourzadeh ${ }^{a}$, S. Ebrahimnejad ${ }^{\text {b,* }}$, K. Khalili-Damghani ${ }^{\mathrm{a}}$, and A. Hafezalkotob \\ a. Department of Industrial Engineering, South Tehran Branch, Islamic Azad University, Tehran, Iran. \\ b. Department of Industrial Engineering, Karaj Branch, Islamic Azad University, Karaj, P.O. Box 31485/313, Iran.
}

Received 27 July 2019; received in revised form 22 July 2020; accepted 14 September 2020

\author{
KEYWORDS \\ Hub location problem; \\ Robust optimization; \\ Chance-constrained \\ programming; \\ Cooperative \\ competitive \\ environment; \\ Multivariate Lagrange \\ interpolation function.
}

\begin{abstract}
In this paper, an integer programming model is offered for capacitated multiallocation median hub location problems applicable to both cooperative and competitive environments among airlines. We divided the hubs into six independent categories by comparing the parameters of ticket price, travel time, and service quality for both the follower and leader airlines. The degrees of importance for the parameters of time and cost were determined by a multivariate Lagrange interpolation method, which could be of significant help in allocating travelers to the follower airline hubs. Then, with regard to the seasonal demand of travelers, travel demand was considered as an uncertain parameter. To identify the deterministic equivalent forms for the considered categories of hub location models, the robust optimization method and the chance-constrained programming model were employed. Finally, the developed model was tested for a case study. The results indicated that the coalition of follower airlines could absorb nearly $2 \%$ of the leader airline travelers with relatively lower travel cost and time.
\end{abstract}

(C) 2022 Sharif University of Technology. All rights reserved.

\section{Introduction}

Since networks have a hierarchical structure, performing several travels from lower levels in demand spokes (origins) to lower levels in destination spokes is not cost-effective for companies due to the low demand level. In such cases, it is better to establish flows from other points, which are called hubs [1]. Hub location as an indirect transportation problem requires designing an efficient network. This applies when there

\footnotetext{
*. Corresponding author.

E-mail addresses: st_f_noorzadeh@azad.ac.ir (F.

Nourzadeh); ibrahimnejad@kiau.ac.ir (S. Ebrahimnejad);

kaveh.khalili@gmail.com (K. Khalili-Damghani);

hafezalkotob@iust.ac.ir (A.Hafezalkotob)
}

is a need for economies of scale in transportation or communication.

Today, hub location can be adopted for transportation problems [2], postal service [3], order distribution [4], emergency services [5], and computer networks [6].

In the real world, transportation occurs via hubs in a competitive market, where several service providers compete with each other on gaining more market share. Accordingly, customers can choose one of them based on freight, service delivery time, type of offered services, and so on. Marianov et al. [7] proposed the first hub location problem in a competitive environment. In their model for the hub location of the follower player, the leader player had already selected its huband-spoke network. The proposed model used fewer variables and constraints than the previous location 
problems. The flow from origin to destination passed through only one path (including the maximum of two hubs). They showed that using more hubs would lead to lower costs. They also presented two models for the follower player. In the first model, if the cost of traveler movement by the follower player was lower than that by the leader player, then all of the travelers were attracted to the leader player hub. However, in the second model, three capture sets were presented based on the compared costs of travel by the follower and leader players, who attracted $50 \%, 75 \%$, and $100 \%$ of travelers.

By changing the two models of Marianov et al. [7], Wagner [8] reduced the time needed to achieve an optimal solution to problems with more than 50 spokes and 5 hubs. He developed the capture sets to offer six cases based on the fact that flow from origin to destination passed through one or two paths.

Marianov et al. [7] and Wagner [8] used the values of $0.7,0.9$, and 1.1 as well as $50 \%, 75 \%$, and $100 \%$ in their capture sets. They employed a multinomial Lagrange interpolation method in order to calculate exact values. The members of the capture sets of the follower airlines were determined by comparing the parameters of travel cost and time between the hubs of the leader and follower airline as well as service quality of the airports under their control. Moreover, the bounds of variables that belonged to these sets were determined by considering the degrees of importance of the parameters of travel time and travel cost from the viewpoint of travelers, the quality of airports and airlines, safety, and delays of airlines.

To identify the members of the capture sets, Marianov et al. [7] and Wagner [8] only compared the costs of moving a traveler by the follower and leader players. However, aside from the movement cost of a traveler, there are other parameters such as travel time and service quality of hubs (airports) in the real world, which can be a basis for the selection of players and hubs. To overcome the aforementioned shortcoming and determine the members of capture sets more accurately, in the present study, we compare travel times and the costs incurred by the travelers of each player. Additionally, comparing the service quality of hubs under the control of players is the cornerstone of our research.

In real-world situation, ignoring even one small uncertainty in data will result in an insignificant and meaningless (non-)optimal solution. Therefore, various approaches have been put forward in the literature to gain more realistic optimal solutions. Chanceconstrained programming and robust optimization are the most important approaches in this area. Soyster [9], Ben-Tal and Nemirovski [10], and Bertsimas and Sim [11] have presented the main approaches for robust optimization, which are employed in the research on hub location under uncertainty. In regard to the possibility of controlling the conservativeness of robust solutions and linearity of the Bertsimas and Sim method [11], we adopt this approach and chanceconstrained programming in order to demonstrate the uncertainty in travel demand for achieving more realistic solutions and then, compare the results.

The increase in the foreign air travelers to Iran [12] led us to the issue of organizing the travelers and determining the exact location of hubs. With this in mind, we developed the model of Marianov et al. [7] by defining a new type of capture sets under uncertainty for an alliance of airlines with a lower market share. In the proposed model, we present an optimal hub-and-spoke network for follower airlines in which their share of the travelers market increases in competition with other airlines through alliance. By comparing the parameters of time and cost of travel by the follower and leader airlines as well as service quality of the airports under their control, we divided hub sets of the follower airlines into six categories to generate the travelers' decision options and reduce the complexity of modeling. By adopting a multivariate Lagrange interpolation method, we determined the degrees of importance for the time and cost of travel from the perspective of the travelers. In the proposed model, spokes were demand points that could travel by using the hubs of the follower airlines. Finally, we examined a case study in which the Emirates airline was the leader airline and the follower airlines consisted of Mahan Airline, Iran Air, and Aseman Airline. The spokes were selected from a pool of cities, which passed the largest numbers of travelers from the European countries to the East Asian countries by the hubs of the Emirates airline. The results showed that the income of the follower airlines experienced a considerable growth compared to the Marianov et al. [7] model and could absorb nearly $2 \%$ of the travelers of the leader airline due to lower travel cost and time.

In the next section, the literature related to the area under study is reviewed. Section 3 presents a model for capacitated multiple-allocation median hub location in both cooperative and competitive environments. Then, to determine the degrees of importance for travel time and cost, a multivariate Lagrangian interpolation function is introduced. In Sections 4 and 5 , the introduced model will be presented under uncertainty by employing robust optimization and chanceconstrained programming approaches, separately. In Section 6, deterministic equivalent forms adopted from the robust optimization and chance-constrained programming approaches are tested in a case study. Also, the impact of change in the parameters of the problem on the value of the objective function will be investigated. Finally, some concluding remarks will be presented in the last section of the present paper. 


\section{Literature review}

The most important research related to the subject of this paper is presented in the following. Sasaki and Fukushima [13] proposed a new model called "Stackelberg Hub Location" to explore the competition among a large company and several medium-size firms in which space solution was considered as a Continuous Space. They suggested that a leader company could lose a huge percentage of its travelers if they disregard the competition strategies. Based on the Stackelberg hub location model [13], Sasaki [14] designed a hub network in which two companies competed over maximizing their profits and their solution space was like a network. To avoid unprofitable services, he added a flow threshold constraint and considered the effect of the model given the abovementioned constraints and strategies of players. The results indicated that the flow threshold constraint was one of the most important factors in hub network design. Sasaki et al. [15] proposed a model for hub location in a competitive environment. Whereas Sasaki and Fukushima [13] and Sasaki [14] allowed using only one hub in the flow path from origin to destination, they studied more than one hub in their model. Eiselt and Marianov [16] proposed a hub location problem in a competitive environment in which customers based on the parameters of ticket price and flight time used the gravity-like function to select airlines. While in the previous models, the flow passing from origin to destination should only pass through one pat, the model offered by Eiselt and Marianov [16] allowed flows passing from origin to destination through different paths and hubs. They implemented their model for the follower player as a new entrant player to the Australian postal network.

Code Sharing Agreement is a commercial agreement in air transportation, in which two or more airlines share a common flight. In this paper, we consider the alliance between Mahan Airline, Iran Air, and Aseman Airline using Code Sharing Agreement. Lin [17] assessed the economic effects of alliance and cooperation between an international airline and a local airline. He suggested that two Stackelberg equilibrium points were achievable when a set of allied airlines was identified as the leader (or follower) player. Lin also demonstrated that in addition to an increase in the social welfare of travelers, the alliance might reduce international traveler excess and local direct travelers. Zou and Chen [18] investigated the effects of code sharing and global alliance on the performance of airlines, simultaneously. The results from a group of 81 airlines during the 2007-2012 period showed that the profit margin of an airline was positively associated with a few number of partners in code sharing. Yimga [19] investigated the relationship between alliances and on-time performance. He found evidence that code-sharing alliances would improve the on-time performance rate and allow for more efficient connections between flights. More efficient connections decrease the total travel time and thereby, increase the quality of a flight.

Adibi and Razmi [20] developed a two-stage stochastic programming for formulating stochastic uncapacitated multiple-allocation HLP in Iran. They considered three cases wherein: (1) flow was stochastic, (2) cost was stochastic, and (3) both flow and cost were stochastic. To evaluate their formulations, they used a case study based on the ten-node network of top cities of the air transportation network in Iran. Boukani et al. [21] developed two mathematical models for the capacitated single- and multiple-allocation p-hub median problems. They presented a robust optimization approach in order to consider uncertainty in the fixed cost of hub establishment and capacity of each hub. They showed that costs would increase when uncertainties were not considered in the model. An integrated hub location and revenue management problem was considered by Tikani et al. [22]. They presented a twostage stochastic programming formulation to maximize the revenue made out of the transportation network and minimize hub installation costs. In the first stage, hub location, the link between the hub and the nonhub, and the protection level of tickets for different booking classes were determined. The booking limit of tickets could be obtained in the second stage. The demand was captured in a set of discrete scenarios under the average case. Robust optimization was proposed to handle the uncertainty in the demands of customer classes. The problem was demonstrated in the airline industry. Their results showed the efficiency of their methods for the instances with up to 25 nodes.

Nikoofal and Sadjadi [23] used the Bertimas and Sim's approach [11] to propose a robust model of the median hub location problem with uncertain travel costs. They compared the performance of the model with that of the min-max regret approach. Taking advantage of Bertsimas and Sim's approach [11], GhaffariNasab et al. [24] proposed a robust model for the capacitated hub location problem (single allocationmultiple allocation) in which demand change was uncertain. They used uncertain demand only for capacity constraints and supposed that the objective function of demand was certain. Zetina et al. [25] proposed a robust counterpart for multiple-hub location problem in which (like Bertsimas and Sim's approach [11]) the level of conservativeness was controlled by using uncertainty budget. The problem was modeled in three modes: uncertain transportation cost, uncertain demand, and both simultaneously.

Chance-constrained programming was first introduced by Charnes and et al. [26]. Gao and Qin [27] developed a chance-constrained programming approach 
for p-hub center location problems under uncertain setting by characterizing travel time as an uncertain variable. Chance-constrained programming is often applicable to conditions where there is uncertainty in the data and parameters [28]. It is well known that when random input has a joint normal distribution, it can be reduced to a convex problem. Thus, it can be solved efficiently via convex programming techniques [29]. Accordingly, many problems in various areas can be formulated as chance-constrained programing. A series of applications has been reviewed in the literature [30].

\section{Deterministic model formulation}

In this section, we propose a new formulation for the capacitated multi-allocation median hub location problem in both cooperative and competitive environments. Then, sets, parameters, variables, objective function, and constraints of the model are presented. The notation used for the proposed deterministic model is presented in Table 1.

\subsection{Objective function}

The first term of the objective function Eq. (1) represents the total income from selling tickets to travelers passing from origin $i$ (per each origin) to destination $j$ (to all destinations) through hubs $k$ of the follower airline. Accordingly, none of the hubs controlled by the follower airlines can be the origin or destination of travel. The second term of the objective function Eq. (1) represents the total income from selling tickets to travelers whose destinations are one of the hubs of the follower airlines. The third term of the objective function Eq. (1) represents the total income from selling tickets to travelers whose origins are one of the hubs of the follower airlines.

$$
\begin{aligned}
z= & \max \sum_{k \in K} \sum_{i \in I-K} \sum_{j \neq i \in J-K} \sum_{s=1}^{2}\left(x_{k j}^{i s}+y_{k j}^{i s}+z_{k j}^{i s}\right) \\
& \left(\gamma_{1} c_{i k}+\beta_{1} c_{k j}\right) \\
& +\sum_{i \in I-K} \sum_{j \in K} \sum_{s=1}^{2}\left(x_{j j}^{i s}+y_{j j}^{i s}+z_{j j}^{i s}\right)\left(\gamma_{2} c_{i j}\right) \\
& +\sum_{k \in K} \sum_{j \in J-K} \sum_{s=1}^{2}\left(x_{k j}^{k s}+y_{k j}^{k s}+z_{k j}^{k s}\right)\left(\beta_{2} c_{k j}\right) \\
& \left(\beta_{1} \leq \gamma_{1} \leq \beta_{2} \leq \gamma_{2}\right) .
\end{aligned}
$$

Here is the reason why there is a relationship between ticket prices in the objective function Eq. (1) such that $\beta_{1} \leq \gamma_{1} \leq \beta_{2} \leq \gamma_{2}$. When travelers use any other origin of the follower airline hubs to reach any other destination of the follower airline hubs, their profitability for the airlines will be higher and they deserve more discount. In other words, $\beta_{1}, \gamma_{1} \leq \gamma_{2}$ and $\beta_{1}, \gamma_{1} \leq \beta_{2}$. In this way, since travelers use a follower airline hub in the second part of their travel, airport costs are decreased. Also, because travelers from different origins aim to reach the same destination, taking advantage of a bigger airplane with lower ticket prices seems more logical; therefore $\beta_{1} \leq \gamma_{1}$. When the origin or destination is one of the follower airline hubs, the amount of discount is lower due to shorter travel. Thus, when the origin is a follower airline hub, we have $\beta_{2} \leq \gamma_{2}$. Because airport costs are lower, travelers from other origins are going to reach the aforementioned destination.

\subsection{Constraints}

Constraints (2) to (7) show that the flow is established when a hub exists:

$$
\begin{array}{ll}
\sum_{k \in N_{i j}^{1}} x_{k j}^{i 1} \leq W_{i j} * p_{1} & \forall i \in I, \quad j \in J, \\
\sum_{k \in N_{i j}^{2}} x_{k j}^{i 2} \leq W_{i j} * p_{2} & \forall i \in I, \quad j \in J, \\
\sum_{k \in M_{i j}^{1}} y_{k j}^{i 1} \leq W_{i j} * q_{1} & \forall i \in I, \quad j \in J, \\
\sum_{k \in M_{i j}^{2}} y_{k j}^{i 2} \leq W_{i j} * q_{2} & \forall i \in I, \quad j \in J, \\
\sum_{k \in P_{i j}^{1}} z_{k j}^{i 1} \leq W_{i j} * r_{1} & \forall i \in I, \quad j \in J, \\
\sum_{k \in P_{i j}^{2}} z_{k j}^{i 2} \leq W_{i j} * r_{2} & \forall i \in I, \quad j \in J .
\end{array}
$$

According to Constraint (8), the maximum flow passing from all origins to all destinations through follower airline hubs equals $\left[W_{i j}\left(\frac{U_{f}}{U_{l}}\right)\left(\frac{S_{f}}{S_{l}}\right)\left(\frac{t_{l}}{t_{f}}\right)\right]$. Also, this constraint shows multiple allocations:

$$
\begin{aligned}
& \sum_{s=1}^{2}\left(\sum_{k \in K} x_{k j}^{i s}+\sum_{k \in K} y_{k j}^{i s}+\sum_{k \in K} z_{k j}^{i s}\right) \\
& \quad \leq W_{i j}\left(\frac{U_{f}}{U_{l}}\right)\left(\frac{S_{f}}{S_{l}}\right)\left(\frac{t_{l}}{t_{f}}\right) \quad \forall i, j .
\end{aligned}
$$

Constraint (9) shows that the maximum incoming flow to hub $K$ equals $\Gamma_{k}$ :

$$
\sum_{i \in I} \sum_{j \neq i \in J} \sum_{s=1}^{2} x_{k j}^{i s}+y_{k j}^{i s}+z_{k j}^{i s} \leq \Gamma_{k} h_{k} \quad \forall k \in K .
$$

Constraint (10) shows that the minimum flow passing for using spoke $k$ as a hub is equal to $E_{K}$ : 
Table 1. The notation used in the proposed deterministic model.

$$
\begin{aligned}
& \text { Sets: } \\
& N_{i j}^{1}=\left\{k \in K \mid c_{i k}+c_{k j}<C_{i j}, t_{i k}+t_{k}+t_{k j} \geq T_{i j}, V_{k}<V\right\} \\
& N_{i j}^{2}=\left\{k \in K \mid c_{i k}+c_{k j}<C_{i j}, t_{i k}+t_{k}+t_{k j} \geq T_{i j}, V_{k} \geq V\right\} \\
& M_{i j}^{1}=\left\{k \in K \mid c_{i k}+c_{k j} \geq C_{i j}, t_{i k}+t_{k}+t_{k j}<T_{i j}, V_{k}<V\right\} \\
& M_{i j}^{2}=\left\{k \in K \mid c_{i k}+c_{k j} \geq C_{i j}, t_{i k}+t_{k}+t_{k j}<T_{i j}, V_{k} \geq V\right\} \\
& P_{i j}^{1}=\left\{k \in K \mid c_{i k}+c_{k j}<C_{i j}, t_{i k}+t_{k}+t_{k j}<T_{i j}, V_{k}<V\right\} \\
& P_{i j}^{2}=\left\{k \in K \mid c_{i k}+c_{k j}<C_{i j}, t_{i k}+t_{k}+t_{k j}<T_{i j}, V_{k} \geq V\right\} \\
& K^{\prime}=N_{i j}^{1} \cup N_{i j}^{2} \\
& K^{\prime \prime}=M_{i j}^{1} \cup M_{i j}^{2} \\
& K^{\prime \prime \prime}=P_{i j}^{1} \cup P_{i j}^{2} \\
& K=K^{\prime} \cup K^{\prime \prime} \cup K^{\prime \prime \prime}
\end{aligned}
$$

\begin{tabular}{|c|c|}
\hline \multicolumn{2}{|l|}{ Parameters: } \\
\hline$c_{i k}$ & r passing a traveler from origin $i$ to hub $k$ by the follower airlines \\
\hline$c_{k j}$ & Ticket price for passing a traveler from hub $k$ to destination $j$ by the follower airlines \\
\hline$C_{i j}$ & Total airfare of passing a traveler from origin $i$ to destination $j$ through the leader hub(s) \\
\hline$t_{k}$ & Average travel time delay for transferring travelers at the airport $k$ \\
\hline$t_{i k}$ & Time needed to pass travelers from origin $i$ to hub $k$ by the follower airlines \\
\hline$t_{k j}$ & Time needed to pass travelers from hub $k$ to destination $j$ by the follower airlines \\
\hline$T_{i j}$ & Total time needed to pass from origin $i$ to destination $j$ by the leader hub(s) \\
\hline$W_{i j}$ & Total flow passing from origin $i$ to destination $j$, which has already moved by the leader \\
\hline$\Gamma_{k}$ & Capacity of hub $k$ \\
\hline$E_{k}$ & Minimum passing flow to consider spoke $k$ as a hub \\
\hline$V_{k}$ & Service quality of airport $k$ controlled by a follower airline \\
\hline$V$ & Average service quality of airports controlled by the leader airline \\
\hline$U_{f}$ & Quality of follower airline \\
\hline$U_{l}$ & Quality of leader airline \\
\hline$S_{f}$ & Safety of follower airline \\
\hline$S_{l}$ & Safety of leader airline \\
\hline$t_{f}$ & The average travel time delay to transfer travelers by the follower airlines \\
\hline$t_{l}$ & The average travel time delay to transfer travelers by the leader airline \\
\hline$f_{c}$ & Importance of cost for traveler \\
\hline$f_{t}$ & Importance of time for traveler \\
\hline$f_{q}$ & Importance of service quality of airport for traveler \\
\hline$M$ & Large positive number \\
\hline $0 \leq p_{1}<p_{2} \leq 1$ & Reduction factor of $W_{i j}$ for sets $N_{i j}^{1}, N_{i j}^{2}$ \\
\hline $0 \leq q_{1}<q_{2} \leq 1$ & Reduction factor of $W_{i j}$ for sets $M_{i j}^{1}, M_{i j}^{2}$ \\
\hline $0 \leq r_{1}<r_{2} \leq 1$ & Reduction factor of $W_{i j}$ for sets $P_{i j}^{1}, P_{i j}^{2}$ \\
\hline $0<\beta_{1}, \beta_{2}, \gamma_{1}, \gamma_{2} \leq 1$ & Discount factor for ticket price \\
\hline
\end{tabular}

\section{Indices:}

$I, i \quad$ Set and number of origin points

$J, j \quad$ Set and number of destination points

$K, k \quad$ Set and number of all hubs of the follower airlines 
Table 1. The notation used in the proposed deterministic model (continued).

\begin{tabular}{ll}
\hline \multicolumn{2}{l}{ Decision variables: } \\
$h_{k} \quad$ Equals 1 if spoke $k$ is selected as a hub, zero otherwise \\
$x_{k j}^{i 1}$ & Amount of passing flow by the follower from origin $i$ to destination $j$ through hub $k \in N_{i j}^{1}$ \\
$x_{k j}^{i 2}$ & Amount of passing flow by the follower from origin $i$ to destination $j$ through hub $k \in N_{i j}^{2}$ \\
$y_{k j}^{i 1}$ & Amount of passing flow by the follower from origin $i$ to destination $j$ through hub $k \in M_{i j}^{1}$ \\
$y_{k j}^{i 2}$ & Amount of passing flow by the follower from origin $i$ to destination $j$ through hub $k \in M_{i j}^{2}$ \\
$z_{k j}^{i 1}$ & Amount of passing flow by the follower from origin $i$ to destination $j$ through hub $k \in P_{i j}^{1}$ \\
$z_{k j}^{i 2}$ & Amount of passing flow by the follower from origin $i$ to destination $j$ through hub $k \in P_{i j}^{2}$ \\
\hline
\end{tabular}

$$
E_{k}-\sum_{i \in I} \sum_{j \in J} \sum_{s=1}^{2}\left(x_{k j}^{i s}+y_{k j}^{i s}+z_{k j}^{i s}\right) \leq M\left(1-h_{k}\right)
$$

$\forall k \in K$.

Constraint (11) guarantees that for each origin $i$ and destination $j$, only variables $x_{k j}^{i s}$ related to airports $k$ in the set $K^{\prime}$ can be non-zero and the remaining variables are equal to zero:

$$
\begin{aligned}
x_{k j}^{i s} & =0 \\
& \forall i \in I, \quad j \in J ; \quad \forall s=1,2 ; \quad k \in K-K^{\prime} .
\end{aligned}
$$

Constraint (12) guarantees that for each origin $i$ and destination $j$, only variables $y_{k j}^{i s}$ related to airports $k$ in set $K^{\prime \prime}$ can be non-zero and the remaining variables are equal to zero:

$$
\begin{aligned}
y_{k j}^{i s} & =0 \\
& \forall i \in I, \quad j \in J ; \quad \forall s=1,2 ; \quad k \in K-K^{\prime \prime} .
\end{aligned}
$$

Constraint (13) guarantees that for each origin $i$ and destination $j$, only variables $z_{k j}^{i s}$ related to airports $k$ in set $K^{\prime \prime \prime}$ can be non-zero and the remaining variables are equal to zero:

$$
\begin{aligned}
z_{k j}^{i s} & =0 \\
& \forall i \in I, \quad j \in J ; \quad \forall s=1,2 ; \quad k \in K-K^{\prime \prime \prime} .
\end{aligned}
$$

Constraints (14) and (15) show the domain of variables:

$$
\begin{aligned}
& h_{k} \in\{0,1\} \quad \forall k \in K, \\
& x_{k j}^{i 1}, x_{k j}^{i 2}, y_{k j}^{i 1}, y_{k j}^{i 2}, z_{k j}^{i 1}, z_{k j}^{i 2} \in I^{+} \cup\{0\} \\
& \forall i \in I, \quad j \in J, \quad k \in K .
\end{aligned}
$$

\subsection{Determining the importance of travel time, travel cost, and service quality of hubs}

$f_{c}, f_{t}$, and $f_{q}$ represent the degrees of importance for the parameters of travel time, travel cost, and service quality of hubs for travelers. To determine them, we use data gathered by questionnaires from air travelers with different income levels, ages, and travel purposes. Also, we introduce the interpolation function of importance for time and cost in air travels by using a multivariate Lagrange interpolation method. Lagrange interpolation function with $m$ variables and degree $n$ is defined as Eq. (16) [31]:

$$
f\left(X_{1}, X_{2}, \cdots, X_{m}\right)=\sum_{e_{i} .1 \leq n} \alpha_{e_{i}} X^{e_{i}},
$$

where $e_{i}=\left(e_{1 i}, \cdots, e_{m i}\right)$ and $\sum_{j=1}^{m} e_{j i}=1$.

To uniquely determine $f$, we require:

$$
\rho=\left(\begin{array}{c}
n+m \\
n
\end{array}\right)
$$

independent points in Eq. (17):

$$
\begin{aligned}
& \left(x_{1, i}, \cdots, x_{m, i}, f_{i}\right) \in R^{m+1}, \quad 1 \leq i \leq \rho, \\
& f_{i}=f\left(x_{1, i}, \cdots, x_{m, i}\right) .
\end{aligned}
$$

By calculating the degrees of importance for travel time, travel cost, and service quality of airport and by taking quality, safety, and travel time delay of the follower and leader airlines into account, parameters $p_{1}, p_{2}, q_{1}, q_{2}, r_{1}$, and $r_{2}$ are determined by Eq. (18):

$$
\begin{aligned}
& p_{1}=f_{c} *\left(\frac{U_{f}}{U_{l}}\right) *\left(\frac{S_{f}}{S_{l}}\right) *\left(\frac{t_{l}}{t_{f}}\right), \\
& p_{2}=\left(f_{c}+f_{q}\right) *\left(\frac{U_{f}}{U_{l}}\right) *\left(\frac{S_{f}}{S_{l}}\right) *\left(\frac{t_{l}}{t_{f}}\right), \\
& q_{1}=f_{t} *\left(\frac{U_{f}}{U_{l}}\right) *\left(\frac{S_{f}}{S_{l}}\right) *\left(\frac{t_{l}}{t_{f}}\right), \\
& q_{2}=\left(f_{t}+f_{q}\right) *\left(\frac{U_{f}}{U_{l}}\right) *\left(\frac{S_{f}}{S_{l}}\right) *\left(\frac{t_{l}}{t_{f}}\right), \\
& r_{1}=\left(f_{c}+f_{t}\right) *\left(\frac{U_{f}}{U_{l}}\right) *\left(\frac{S_{f}}{S_{l}}\right) *\left(\frac{t_{l}}{t_{f}}\right), \\
& r_{2}=\left(f_{c}+f_{t}+f_{q}\right) *\left(\frac{U_{f}}{U_{l}}\right) *\left(\frac{S_{f}}{S_{l}}\right) *\left(\frac{t_{l}}{t_{f}}\right) .
\end{aligned}
$$




\section{Robust optimization}

In this section, we present the robust counterpart of the model proposed in the previous section by employing the Bertsimas and Sim's approach [11]. Given the impact of seasonal changes (e.g., travel in high season) and weather conditions on the number of travelers, we consider $w_{i j}$ as uncertain. The values of the uncertain parameter $\tilde{w}_{i j}$ are selected based on a symmetric distribution in the interval $\left[w_{i j}-\widehat{w}_{i j}, w_{i j}+\widehat{w}_{i j}\right]$ with an average of $w_{i j}$.

The notation used in the proposed robust model is presented in Table 2.

\subsection{Robust model formulation}

Given that uncertain parameters $w_{i j}$ are included in Constraints (2) to (8), we employ the Bertsimas and Sim's approach [11] and by defining the variable $H$, we show the abovementioned constraints in the form of Constraints (19) to (26):

$$
\begin{aligned}
& \sum_{k \in N_{i j}^{1}} x_{k j}^{i 1}-W_{i j}\left(f_{c}\right)\left(\frac{U_{f}}{U_{l}}\right)\left(\frac{S_{f}}{S_{l}}\right)\left(\frac{t_{l}}{t_{f}}\right) H \leq 0 \\
& \forall i \in I, \quad j \in J, \\
& \sum_{k \in N_{i j}^{2}} x_{k j}^{i 2}-W_{i j}\left(f_{c}+f_{q}\right)\left(\frac{U_{f}}{U_{l}}\right)\left(\frac{S_{f}}{S_{l}}\right)\left(\frac{t_{l}}{t_{f}}\right) H \leq 0 \\
& \forall i \in I, \quad j \in J, \\
& \sum_{k \in M_{i j}^{1}} y_{k j}^{i 1}-W_{i j}\left(f_{t}\right)\left(\frac{U_{f}}{U_{l}}\right)\left(\frac{S_{f}}{S_{l}}\right)\left(\frac{t_{l}}{t_{f}}\right) H \leq 0 \\
& \forall i \in I, \quad j \in J, \\
& \sum_{k \in M_{i j}^{2}} y_{k j}^{i 2}-W_{i j}\left(f_{t}+f_{q}\right)\left(\frac{U_{f}}{U_{l}}\right)\left(\frac{S_{f}}{S_{l}}\right)\left(\frac{t_{l}}{t_{f}}\right) H \leq 0 \\
& \forall i \in I, \quad j \in J,
\end{aligned}
$$

$$
\begin{aligned}
& \sum_{k \in P_{i j}^{1}} z_{k j}^{i 1}-W_{i j}\left(f_{c}+f_{t}\right)\left(\frac{U_{f}}{U_{l}}\right)\left(\frac{S_{f}}{S_{l}}\right)\left(\frac{t_{l}}{t_{f}}\right) H \leq 0 \\
& \forall i \in I, \quad j \in J, \\
& \sum_{k \in P_{i j}^{2}} z_{k j}^{i 2} \leq W_{i j}\left(f_{c}+f_{t}+f_{q}\right)\left(\frac{U_{f}}{U_{l}}\right)\left(\frac{S_{f}}{S_{l}}\right)\left(\frac{t_{l}}{t_{f}}\right) H \leq 0 \\
& \forall i \in I, \quad j \in J, \\
& \sum_{s=1}^{2}\left(\sum_{k \in K} x_{k j}^{i s}+\sum_{k \in K} y_{k j}^{i s}+\sum_{k \in K} z_{k j}^{i s}\right) \\
& \quad-W_{i j}\left(\frac{U_{f}}{U_{l}}\right)\left(\frac{S_{f}}{S_{l}}\right)\left(\frac{t_{l}}{t_{f}}\right) H \leq 0 \\
& \forall i \in I, \quad j \in J, \\
& 1 \leq H \leq 1 .
\end{aligned}
$$

Given that Constraints (19) to (26) are defined for each $i$ and each $j$, they are themselves subject to the maximum $i \times j$ constraint. Moreover, since each of these constraints has only one $w_{i j}$, we have $\Gamma_{i j}^{\text {const }} \in\left[0,\left|F^{\text {const }}\right|\right]$, where $F^{\text {const }} \subseteq\{0,1\}$. Based on the research conducted by Bertsimas and Sim [11], Constraint (19) can turn into Constraint (27):

$$
\begin{aligned}
& \sum_{k \in N_{i j}^{1}} x_{k j}^{i 1}-W_{i j}\left(f_{c}\right)\left(\frac{U_{f}}{U_{l}}\right)\left(\frac{S_{f}}{S_{l}}\right)\left(\frac{t_{l}}{t_{f}}\right) H \\
& +\max _{\forall(i, j) \in F^{1}}\left\{\left\lfloor\Gamma_{i j}^{1}\right\rfloor \widehat{w}_{i j}\left(f_{c}\right)\left(\frac{U_{f}}{U_{l}}\right)\left(\frac{S_{f}}{S_{l}}\right)\left(\frac{t_{l}}{t_{f}}\right) H\right. \\
& \left.+\left(\Gamma_{i j}^{1}-\left\lfloor\Gamma_{i j}^{1}\right\rfloor\right) \widehat{w}_{i j}\left(f_{c}\right)\left(\frac{U_{f}}{U_{l}}\right)\left(\frac{S_{f}}{S_{l}}\right)\left(\frac{t_{l}}{t_{f}}\right) H\right\} \\
& \leq 0 \quad \forall i \in I, \quad j \in J .
\end{aligned}
$$

Similarly, Constraints (20) to (26) are modified.

Table 2. The notation used in the proposed robust model.

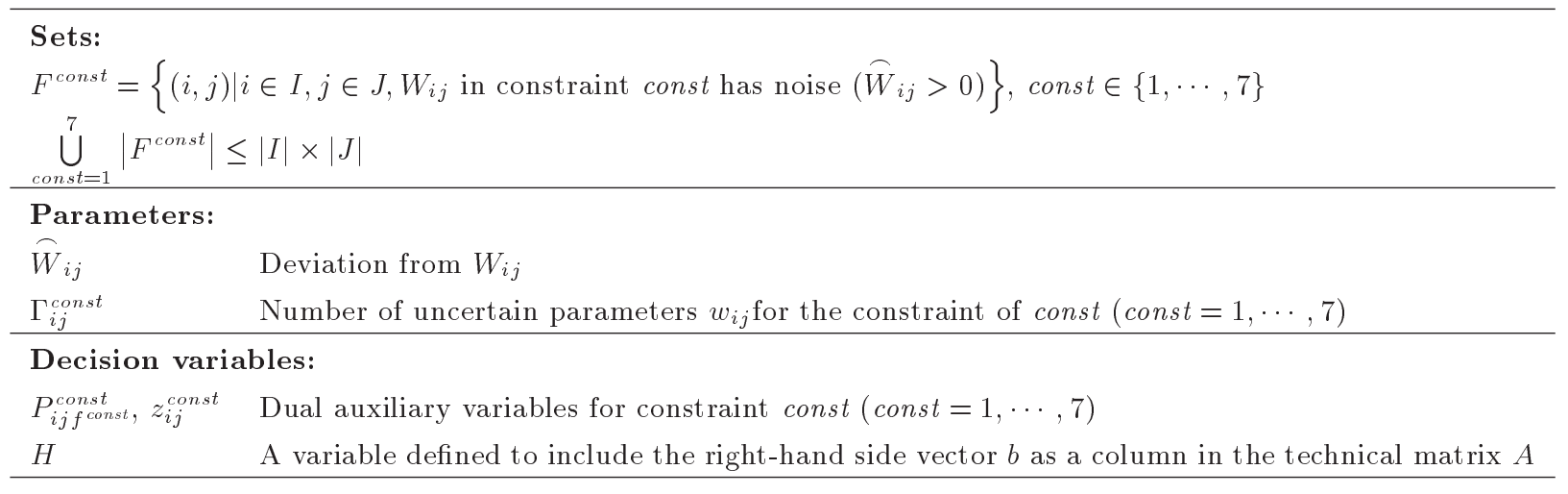


Then, by proving Theorem 1, we can show that Constraint (27) is equal to a linear optimization problem. The way of proving the theorem for other similar constraints is the same.

Theorem 1. For providing $H^{*}$, Function (28):

$$
\begin{aligned}
& \beta_{1}\left(H^{*}, \Gamma_{i j}^{1}\right) \\
& =\max _{\forall(i, j) \in F^{1}}\left\{\left\lfloor\Gamma_{i j}^{1}\right\rfloor \widehat{w}_{i j}\left(f_{c}\right)\left(\frac{U_{f}}{U_{l}}\right)\left(\frac{S_{f}}{S_{l}}\right)\left(\frac{t_{l}}{t_{f}}\right) H^{*}\right. \\
& \left.\quad+\left(\Gamma_{i j}^{1}-\left\lfloor\Gamma_{i j}^{1}\right\rfloor\right) \widehat{w}_{i j}\left(f_{c}\right)\left(\frac{U_{f}}{U_{l}}\right)\left(\frac{S_{f}}{S_{l}}\right)\left(\frac{t_{l}}{t_{f}}\right) H^{*}\right\},
\end{aligned}
$$

is equal to the linear programming problem below:

$$
\begin{array}{ll}
\beta_{1}\left(H^{*}, \Gamma_{i j}^{1}\right) & =\max \widehat{w}_{i j}\left(f_{c}\right)\left(\frac{U_{f}}{U_{l}}\right)\left(\frac{S_{f}}{S_{l}}\right)\left(\frac{t_{l}}{t_{f}}\right) H^{*} z_{i j}, \\
\text { s.t. } \quad z_{i j} & \leq \Gamma_{i j}^{1} \\
& 0 \leq z_{i j} \leq 1 \quad \forall(i, j) \in F^{1} .
\end{array}
$$

Proof. We prove the theorem in two cases:

Case 1: $\Gamma_{i j}^{1}$ is an integer. Therefore, $\Gamma_{i j}^{1} \in[0,1]$; then, $\Gamma_{i j}^{1}=1$. In this case, $\beta_{1}\left(H^{*}, \Gamma_{i j}^{1}\right)$ is equal to:

$$
\begin{aligned}
\beta_{1}\left(H^{*}, \Gamma_{i j}^{1}\right) & \\
= & \max _{\forall(i, j) \in F^{1}}\left\{\widehat{w}_{i j}\left(f_{c}\right)\left(\frac{U_{f}}{U_{l}}\right)\left(\frac{S_{f}}{S_{l}}\right)\left(\frac{t_{l}}{t_{f}}\right) H^{*}\right\} \\
= & \widehat{w}_{i j}\left(f_{c}\right)\left(\frac{U_{f}}{U_{l}}\right)\left(\frac{S_{f}}{S_{l}}\right)\left(\frac{t_{l}}{t_{f}}\right) H^{*} .
\end{aligned}
$$

Because the optimization problem is a maximization one, we consider $z_{i j}=\Gamma_{i j}^{1}=1$. Therefore, the problem can become feasible and the optimal value for the objective function is equal to:

$$
\widehat{w}_{i j}\left(f_{c}\right)\left(\frac{U_{f}}{U_{l}}\right)\left(\frac{S_{f}}{S_{l}}\right)\left(\frac{t_{l}}{t_{f}}\right) H^{*} \text {. }
$$

Hence, in this case, Eq. (29) is correct.

Case 2: $\Gamma_{i j}^{1}$ is non-integer. Therefore, $\Gamma_{i j}^{1} \in[0,1]$; then, $\left\lfloor\Gamma_{i j}^{1}\right\rfloor=0$. In this case, $\beta_{1}\left(H^{*}, \Gamma_{i j}^{1}\right)$ is equal to:

$$
\begin{aligned}
& \beta_{1}\left(H^{*}, \Gamma_{i j}^{1}\right) \\
& =\max _{\forall(i, j) \in F^{1}}\left\{\left(\Gamma_{i j}^{1}-0\right) \widehat{w}_{i j}\left(f_{c}\right)\left(\frac{U_{f}}{U_{l}}\right)\left(\frac{S_{f}}{S_{l}}\right)\left(\frac{t_{l}}{t_{f}}\right) H^{*}\right\} \\
& =\Gamma_{i j}^{1} \widehat{w}_{i j}\left(f_{c}\right)\left(\frac{U_{f}}{U_{l}}\right)\left(\frac{S_{f}}{S_{l}}\right)\left(\frac{t_{l}}{t_{f}}\right) H^{*} .
\end{aligned}
$$

Because the optimization problem is a maximization one, we consider $z_{i j}=\Gamma_{i j}^{1}$. Therefore, the problem can become feasible and the optimal value for objective function is equal to:

$$
\Gamma_{i j}^{1} \widehat{w}_{i j}\left(f_{c}\right)\left(\frac{U_{f}}{U_{l}}\right)\left(\frac{S_{f}}{S_{l}}\right)\left(\frac{t_{l}}{t_{f}}\right) H^{*}
$$

Hence, in this case, Eq. (29) is correct.

By using Theorem 1 and taking advantage of the strong duality theorem, it can be shown that the robust counterpart of the robust model presented in Section 3 is the following:

$$
(1,10-15)
$$

$$
\begin{gathered}
\sum_{k \in N_{i j}^{1}} x_{k j}^{i 1}-W_{i j}\left(f_{c}\right)\left(\frac{U_{f}}{U_{l}}\right)\left(\frac{S_{f}}{S_{l}}\right)\left(\frac{t_{l}}{t_{f}}\right) H+z_{i j}^{1} \Gamma_{i j}^{1} \\
+\sum_{f^{1} \in F^{1}} P_{i j f^{1}}^{1} \leq 0 \quad \forall i \in I, \quad j \in J, \\
\sum_{k \in N_{i j}^{2}} x_{k j}^{i 2}-W_{i j}\left(f_{c}+f_{q}\right)\left(\frac{U_{f}}{U_{l}}\right)\left(\frac{S_{f}}{S_{l}}\right)\left(\frac{t_{l}}{t_{f}}\right) H \\
+z_{i j}^{2} \Gamma_{i j}^{2}+\sum_{f^{2} \in F^{2}} P_{i j f^{2}}^{2} \leq 0 \quad \forall i \in I, \quad j \in J,
\end{gathered}
$$

$$
\begin{gathered}
\sum_{k \in M_{i j}^{1}} y_{k j}^{i 1}-W_{i j}\left(f_{t}\right)\left(\frac{U_{f}}{U_{l}}\right)\left(\frac{S_{f}}{S_{l}}\right)\left(\frac{t_{l}}{t_{f}}\right) H+z_{i j}^{3} \Gamma_{i j}^{3} \\
+\sum_{f^{3} \in F^{3}} P_{i j f^{3}}^{3} \leq 0 \quad \forall i \in I, \quad j \in J,
\end{gathered}
$$

$$
\begin{aligned}
\sum_{k \in M_{i j}^{2}} y_{k j}^{i 2}-W_{i j}\left(f_{t}+f_{q}\right)\left(\frac{U_{f}}{U_{l}}\right)\left(\frac{S_{f}}{S_{l}}\right)\left(\frac{t_{l}}{t_{f}}\right) H \\
+z_{i j}^{4} \Gamma_{i j}^{4}+\sum_{f^{4} \in F^{4}} P_{i j f^{4}}^{4} \leq 0 \quad \forall i \in I, \quad j \in J,
\end{aligned}
$$

$$
\begin{aligned}
& \sum_{k \in P_{i j}^{1}} z_{k j}^{i 1}-W_{i j}\left(f_{c}+f_{t}\right)\left(\frac{U_{f}}{U_{l}}\right)\left(\frac{S_{f}}{S_{l}}\right)\left(\frac{t_{l}}{t_{f}}\right) H \\
& +z_{i j}^{5} \Gamma_{i j}^{5}+\sum_{f^{5} \in F^{5}} P_{i j f^{5}}^{5} \leq 0 \quad \forall i \in I, \quad j \in J, \\
& \sum_{k \in P_{i j}^{2}} z_{k j}^{i 2}-W_{i j}\left(f_{c}+f_{t}+f_{q}\right)\left(\frac{U_{f}}{U_{l}}\right)\left(\frac{S_{f}}{S_{l}}\right)\left(\frac{t_{l}}{t_{f}}\right) H \\
& +z_{i j}^{6} \Gamma_{i j}^{6}+\sum_{f^{6} \in F^{6}} P_{i j f^{6}}^{6} \leq 0 \quad \forall i \in I, \quad j \in J,
\end{aligned}
$$




$$
\begin{aligned}
& \sum_{s=1}^{2}\left(\sum_{k \in K} x_{k j}^{i s}+\sum_{k \in K} y_{k j}^{i s}+\sum_{k \in K} z_{k j}^{i s}\right) \\
& \quad-W_{i j}\left(\frac{U_{f}}{U_{l}}\right)\left(\frac{S_{f}}{S_{l}}\right)\left(\frac{t_{l}}{t_{f}}\right) H+z_{i j}^{7} \Gamma_{i j}^{7} \\
& \quad+\sum_{f^{7} \in F^{7}} P_{i j f^{7}}^{7} \leq 0 \quad \forall i, j \\
& \widehat{W}_{i j}\left(\left(f_{c}\right)\left(\frac{U_{f}}{U_{l}}\right)\left(\frac{S_{f}}{S_{l}}\right)\left(\frac{t_{l}}{t_{f}}\right)\right) H \leq z_{i j}^{1}+P_{i j f^{1}}^{1} \\
& \forall i \in I, \quad j \in J, \quad f^{1} \in F^{1}, \\
& \widehat{W}_{i j}\left(\left(f_{c}+f_{q}\right)\left(\frac{U_{f}}{U_{l}}\right)\left(\frac{S_{f}}{S_{l}}\right)\left(\frac{t_{l}}{t_{f}}\right)\right) H \leq z_{i j}^{2}+P_{i j f^{2}}^{2}
\end{aligned}
$$$$
\forall i \in I, \quad j \in J, \quad f^{2} \in F^{2}
$$$$
\widehat{W}_{i j}\left(\left(f_{t}\right)\left(\frac{U_{f}}{U_{l}}\right)\left(\frac{S_{f}}{S_{l}}\right)\left(\frac{t_{l}}{t_{f}}\right)\right) H \leq z_{i j}^{3}+P_{i j f^{3}}^{3}
$$$$
\forall i \in I, \quad j \in J, \quad f^{3} \in F^{3},
$$$$
\widehat{W}_{i j}\left(\left(f_{t}+f_{q}\right)\left(\frac{U_{f}}{U_{l}}\right)\left(\frac{S_{f}}{S_{l}}\right)\left(\frac{t_{l}}{t_{f}}\right)\right) H \leq z_{i j}^{4}+P_{i j f^{4}}^{4}
$$$$
\forall i \in I, \quad j \in J, \quad f^{4} \in F^{4},
$$$$
\widehat{W}_{i j}\left(\left(f_{c}+f_{t}\right)\left(\frac{U_{f}}{U_{l}}\right)\left(\frac{S_{f}}{S_{l}}\right)\left(\frac{t_{l}}{t_{f}}\right)\right) H \leq z_{i j}^{5}+P_{i j f^{5}}^{5}
$$$$
\forall i \in I, \quad j \in J, \quad f^{5} \in F^{5},
$$$$
\widehat{W}_{i j}\left(\left(f_{c}+f_{t}+f_{q}\right)\left(\frac{U_{f}}{U_{l}}\right)\left(\frac{S_{f}}{S_{l}}\right)\left(\frac{t_{l}}{t_{f}}\right)\right) H \leq z_{i j}^{6}+P_{i j f^{6}}^{6}
$$$$
\forall i \in I, \quad j \in J, \quad f^{6} \in F^{6},
$$$$
\widehat{W}_{i j}\left(\left(\frac{U_{f}}{U_{l}}\right)\left(\frac{S_{f}}{S_{l}}\right)\left(\frac{t_{l}}{t_{f}}\right)\right) H \leq z_{i j}^{7}+P_{i j f^{7}}^{7}
$$$$
\forall i \in I, \quad j \in J, \quad f^{7} \in F^{7}
$$$$
1 \leq H \leq 1
$$$$
z_{i j}^{\text {const }}, P_{i j f^{\text {const }}}^{\text {const }} \geq 0
$$$$
\forall i \in I, \quad j \in J, \quad f^{\text {const }} \in F^{\text {const }},
$$$$
\text { const } \in\{1,2, \cdots, 7\} \text {. }
$$

\section{Chance-constrained programming}

In this section, taking into account the uncertain travel demand, we present the deterministic equivalent of the model presented in Section 3 using the chanceconstrained programming approach. Suppose we have a probable scheduling problem as follows:

$$
\begin{array}{ll}
\max z= & \sum_{i=1}^{n} c_{i} x_{i}, \\
\text { s.t.: } \quad & A x \leq d, \\
& P\left(\sum_{i=1}^{n} a_{i} x_{i} \leq \tilde{b}\right) \geq 1-\alpha, \\
& x_{i} \geq 0 \quad i=1, \cdots, n,
\end{array}
$$

where $\tilde{b}$ is an independent random variable and has a normal distribution. It can be shown that the probable constraint $P\left(\sum_{i=1}^{n} a_{i} x_{i} \leq \tilde{b}\right) \geq 1-\alpha$ is equivalent to Constraint (36) [32]:

$$
\sum_{i=1}^{n} a_{i} x_{i} \leq E(\tilde{b})-Z_{1-\alpha} \sqrt{\operatorname{Var}(\tilde{b})}
$$

in which $Z_{1-\alpha}$ represents the point of the standard normal distribution so that $P\left(Z>Z_{1-\alpha}\right)=\alpha$.

Assuming that the parameter $W_{i j}$ of the random variable has normal distribution, it can be deduced from Constraint (36) that Constraints (2) to (8) change in Constraints (37) through (43).

$$
\begin{aligned}
& \sum_{k \in N_{i j}^{1}} x_{k j}^{i 1} \leq E\left(\tilde{W}_{i j}\right) * p_{1}-Z_{1-\alpha} p_{1} * \sqrt{\operatorname{Var}\left(\tilde{W}_{i j}\right)} \\
& \forall i \in I, \quad j \in J
\end{aligned}
$$

$$
\begin{aligned}
& \sum_{k \in N_{i j}^{2}} x_{k j}^{i 2} \leq E\left(\tilde{W}_{i j}\right) * p_{2}-Z_{1-\alpha} p_{2} * \sqrt{\operatorname{Var}\left(\tilde{W}_{i j}\right)} \\
& \forall i \in I, \quad j \in J
\end{aligned}
$$

$$
\begin{aligned}
& \sum_{k \in M_{i j}^{1}} y_{k j}^{i 1} \leq E\left(\tilde{W}_{i j}\right) * q_{1}-Z_{1-\alpha} q_{1} * \sqrt{\operatorname{Var}\left(\tilde{W}_{i j}\right)} \\
& \forall i \in I, \quad j \in J
\end{aligned}
$$

$$
\sum_{k \in M_{i j}^{2}} y_{k j}^{i 2} \leq E\left(\tilde{W}_{i j}\right) * q_{2}-Z_{1-\alpha} q_{2} * \sqrt{\operatorname{Var}\left(\tilde{W}_{i j}\right)}
$$$$
\forall i \in I, \quad j \in J
$$ 


$$
\begin{aligned}
& \sum_{k \in P_{i j}^{1}} z_{k j}^{i 1} \leq E\left(\tilde{W}_{i j}\right) * r_{1}-Z_{1-\alpha} r_{1} * \sqrt{\operatorname{Var}\left(\tilde{W}_{i j}\right)} \\
& \forall i \in I, \quad j \in J \\
& \sum_{k \in P_{i j}^{2}} z_{k j}^{i 2} \leq W_{i j} * r_{2}-Z_{1-\alpha} r_{2} * \sqrt{\operatorname{Var}\left(\tilde{W}_{i j}\right)} \\
& \forall i \in I, \quad j \in J, \\
& \sum_{s=1}^{2}\left(\sum_{k \in K} x_{k j}^{i s}+\sum_{k \in K} y_{k j}^{i s}+\sum_{k \in K} z_{k j}^{i s}\right) \\
& \quad \leq E\left(\tilde{W}_{i j}\right)\left(\frac{U_{f}}{U_{l}}\right)\left(\frac{S_{f}}{S_{l}}\right)\left(\frac{t_{l}}{t_{f}}\right) \\
& \quad-Z_{1-\alpha}\left(\frac{U_{f}}{U_{l}}\right)\left(\frac{S_{f}}{S_{l}}\right)\left(\frac{t_{l}}{t_{f}}\right) * \sqrt{\operatorname{Var}\left(\tilde{W}_{i j}\right)} \quad \forall i, j .
\end{aligned}
$$

\section{Case study}

In this paper, we study a case to examine the proposed model in designing an optimal hub-and-spoke network for a follower airline, in which the Emirates airline is the leader and an alliance consisting of Mahan Airline, Iran Air, and Aseman Airline can play the role of the follower.

\subsection{Determining the importance of travel time, travel cost, and service quality of hubs}

To determine $f_{c}, f_{t}$, and $f_{q}$, we distributed 100 questionnaires to collect opinions of travelers at Imam Khomeini International Airport (with different income levels, ages, and travel purposes) about the importance of travel cost and travel time.

Age and income levels in the developed questionnaire are indicated in Table 3 .

The averages of opinions for travelers with the same income, age, and travel purpose about the degrees of importance of travel time and cost by the type of travel (business, educational, or recreational) are summarized in Tables 4, 5, and 6, respectively.

\begin{tabular}{|c|c|c|c|c|c|}
\hline Age levels & {$[13,20)$} & {$[20,30)$} & {$[30,50)$} & {$[50,75)$} & More than 75 \\
\hline Income levels (\$) & Less than 500 & {$[500,1250]$} & $(1250,3750]$ & More than 3750 & - \\
\hline
\end{tabular}

Using the values in Tables 4 to 6 as well as multivariate Lagrange interpolation method, the quadratic interpolation functions for travel time and cost in air travels are presented as Eqs. (44) [31]:

$$
\begin{aligned}
f_{t w}(x, y)= & -0.016 x^{2}+0.0004 y^{2}+0.014 x y \\
& +1.49 x-0.17 y+20.87
\end{aligned}
$$

Table 3. Age and income levels of travelers.

Table 4. Degrees of the importance for travel time and cost in business travel.

\begin{tabular}{ccccc}
\hline $\begin{array}{c}\text { Number of } \\
\text { travelers }\end{array}$ & $\begin{array}{c}\text { Income level } \\
(\$)\end{array}$ & $\begin{array}{c}\text { Age } \\
\text { level }\end{array}$ & $\begin{array}{c}\text { Degree of the importance } \\
\text { of travel time } \\
(\%)\end{array}$ & $\begin{array}{c}\text { Degree of the importance } \\
\text { of travel cost }\end{array}$ \\
\hline 7 & 950 & 25 & 50 & 55 \\
8 & 6000 & 40 & 80 & 25 \\
6 & 1000 & 43 & 60 & 50 \\
6 & 3000 & 45 & 70 & 30 \\
8 & 7000 & 45 & 90 & 20 \\
9 & 3200 & 60 & 75 & 35 \\
\hline
\end{tabular}

Table 5. Degrees of the importance for travel time and cost in educational travel.

\begin{tabular}{ccccc}
\hline $\begin{array}{c}\text { Number of } \\
\text { travelers }\end{array}$ & $\begin{array}{c}\text { Income level } \\
(\$)\end{array}$ & $\begin{array}{c}\text { Age } \\
\text { level }\end{array}$ & $\begin{array}{c}\text { Degree of the importance } \\
\text { of travel time } \\
(\%)\end{array}$ & $\begin{array}{c}\text { Degree of the importance } \\
\text { of travel cost } \\
(\%)\end{array}$ \\
\hline 3 & 980 & 18 & 25 & 75 \\
2 & 480 & 29 & 20 & 85 \\
4 & 1000 & 27 & 30 & 80 \\
1 & 1700 & 23 & 35 & 60 \\
3 & 900 & 33 & 30 & 85 \\
3 & 2020 & 40 & 40 & 50 \\
\hline
\end{tabular}


Table 6. Degrees of the importance for travel time and cost in recreational travel.

\begin{tabular}{ccccc}
\hline $\begin{array}{c}\text { Number of } \\
\text { travelers }\end{array}$ & $\begin{array}{c}\text { Income level } \\
(\$)\end{array}$ & $\begin{array}{c}\text { Age } \\
\text { level }\end{array}$ & $\begin{array}{c}\text { Degree of the importance } \\
\text { of travel time } \\
(\%)\end{array}$ & $\begin{array}{c}\text { Degree of the importance } \\
\text { of travel cost } \\
(\%)\end{array}$ \\
\hline 6 & 900 & 17 & 35 & 55 \\
9 & 1000 & 25 & 65 & 40 \\
5 & 1100 & 48 & 50 & 50 \\
7 & 450 & 35 & 70 & 20 \\
5 & 8000 & 60 & 90 & 10 \\
8 & 3000 & 77 & 85 & 30 \\
\hline
\end{tabular}

$$
\begin{aligned}
f_{c w}(x, y)= & 0.039 x^{2}+0.013 y^{2}-0.0341 x y \\
& -2.57 x-0.051 y+102.34 \\
f_{t e}(x, y)= & -0.0157 x^{2}-0.087 y^{2}+0.0042 x y \\
& +1.187 x+3.23 y-15.25 \\
f_{c e}(x, y)= & -0.0007 x^{2}-0.164 y^{2}-0.036 x y \\
& +0.97 x+2.73 y+53.07 \\
f_{t h}(x, y)= & -0.18 x^{2}-0.148 y^{2}+0.456 x y+7.67 x \\
& -12.19 y+8.58 \\
& +11.5 y+27.67
\end{aligned}
$$

$$
\begin{array}{ll}
R_{f_{t w}}^{2}=0.9994, & R_{f_{c w}}^{2}=0.995, \quad R_{f_{t e}}^{2}=0.9996, \\
R_{f_{c e}}^{2}=0.9999, \quad R_{f_{t h}}^{2}=0.995, \quad R_{f_{c h}}^{2}=0.9994 .(46)
\end{array}
$$

Given the values for coefficients of determination for Functions (44), it can be stated that these functions interpolate the points in Tables 4, 5, and 6 very accurately. Additionally, one may use them as a basis for calculating the degrees of importance of time and cost for travelers with different ages, income levels, and purposes.

Eq. (47) calculates the average value of Function (45) in their domain of definition:

$$
\begin{aligned}
& \int_{0}^{10000} \int_{13}^{100} f(x, y) d x d y \\
& \quad+\frac{\int_{0}^{10000} \int_{13}^{100}|f(x, y)| d x d y-\int_{0}^{10000} \int_{13}^{100} f(x, y) d x d y}{2} .
\end{aligned}
$$

where $f_{t w}, f_{t e}$, and $f_{t h}$ represent the importance of time and $f_{c w}, f_{c e}$, and $f_{c h}$ denote the importance of cost in business, educational, and recreational travels, respectively.

We use the coefficient of determination $\left(R^{2}\right)$, which is presented as Eq. (45), not only to demonstrate the accuracy of the quadratic Lagrange interpolation functions in Eqs. (44), but also to show that how many opinions about the degrees of importance of travel time and cost are covered by those functions [33]:

$$
R^{2}=1-\frac{\sum_{i=1}^{N}\left(y_{i}-\widehat{y}_{i}\right)^{2}}{\sum_{i=1}^{N}\left(y_{i}-\bar{y}\right)^{2}},
$$

where $N$ is the number of total observations, $y$ is a dependent variable, $\bar{y}$ is the average value of $y$, and $\widehat{y}$ represents the values predicted by the interpolation functions. Using Eq. (45), it can be seen that the more the value of $R^{2}$, the higher the accuracy of the interpolation model will be.

The coefficients of determination for Functions (44) are derived by substituting their values into Eq. (46), which include:

In Eq. (47), it is assumed that negative values are substituted by zero. The second term represents this.

Using Eq. (47), the average values of Function (37) are presented as Eqs. (48) and (49):

$$
\begin{aligned}
& M_{f_{t w}}=67.44, \quad M_{f_{t e}}=16.01, \quad M_{f_{t h}}=56.91, \\
& M_{f_{c w}}=39.31, \quad M_{f_{c e}}=13.36, \quad M_{f_{c h}}=37.89 .
\end{aligned}
$$

The average values in Eqs. (48) and (49) are equal to $47 \%$ and $30 \%$, respectively. Therefore, it can be concluded that travel time has a high priority for nearly $47 \%$ of travelers. Even so, only $30 \%$ of travelers consider travel cost as an important factor. Without loss of generality, one may assume that the remaining $23 \%$ is related to a factor such as quality of airport and its service and others ( $f_{q}$ other than time and cost). Accordingly, we can conclude that the importance of time $\left(f_{t}\right), \operatorname{cost}\left(f_{c}\right)$, and service quality $\left(f_{q}\right)$ for travelers is equal to Eq. (50):

$$
f_{t}=47 \%, \quad f_{c}=30 \%, \quad f_{q}=23 \% .
$$


According to Eq. (51) and assuming that $\frac{U_{f}}{U_{l}}=0.4$, $\frac{S_{f}}{S_{l}}=0.2$, and $\frac{t_{l}}{t_{f}}=0.25$, the values of parameters $p_{1}$, $p_{2}, q_{1}, q_{2}, r_{1}$, and $r_{2}$ are presented as Eqs. (43) by substituting the abovementioned values into Eq. (19):

$$
\begin{aligned}
p_{1} & =f_{c} *\left(\frac{U_{f}}{U_{l}}\right) *\left(\frac{S_{f}}{S_{l}}\right) *\left(\frac{t_{l}}{t_{f}}\right) \\
& =0.3 *(0.4) *(0.2) *(0.25)=0.006 \\
p_{2} & =\left(f_{c}+f_{q}\right) *\left(\frac{U_{f}}{U_{l}}\right) *\left(\frac{S_{f}}{S_{l}}\right) *\left(\frac{t_{l}}{t_{f}}\right) \\
& =(0.3+0.23) *(0.4) *(0.2) *(0.25)=0.011 \\
q_{1} & =f_{t} *\left(\frac{U_{f}}{U_{l}}\right) *\left(\frac{S_{f}}{S_{l}}\right) *\left(\frac{t_{l}}{t_{f}}\right) \\
& =0.47 *(0.4) *(0.2) *(0.25)=0.009 \\
q_{2} & =\left(f_{t}+f_{q}\right) *\left(\frac{U_{f}}{U_{l}}\right) *\left(\frac{S_{f}}{S_{l}}\right) *\left(\frac{t_{l}}{t_{f}}\right) \\
& =(0.47+0.23) *(0.4) *(0.2) *(0.25)=0.014 \\
& =(0.3+0.47) *(0.4) *(0.2) *(0.25)=0.015 \\
r_{1} & =\left(f_{c}+f_{t}\right) *\left(\frac{U_{f}}{U_{l}}\right) *\left(\frac{S_{f}}{S_{l}}\right) *\left(\frac{t_{l}}{t_{f}}\right) \\
&
\end{aligned}
$$

$$
\begin{aligned}
r_{2} & =\left(f_{c}+f_{t}+f_{q}\right) *\left(\frac{U_{f}}{U_{l}}\right) *\left(\frac{S_{f}}{S_{l}}\right) *\left(\frac{t_{l}}{t_{f}}\right) \\
& =(0.3+0.47+0.23) *(0.4) *(0.2) *(0.25)=0.02 .
\end{aligned}
$$

\subsection{Data needed for implementation of the model}

Origins, destinations, and hub candidates of the follower airlines are presented in Tables 7 and 8 .

The service quality of airports, the capacity of hub candidates, and the minimum number of passing travelers to consider a point as a hub are presented in Table 9 .

Based on the first row of Table 9, it is obvious that $V_{k}<V(\forall k)$.

The information summarized in Table 9 has been adjusted for a particular period (October 19-30, 2017).

The weekly average numbers of travelers transferred by the Emirates airport in the first six months of the year 2017 are presented in Table 10. include:

The other necessary input data for the model

- The time and cost of passing travelers between an origin and destination through the Dubai international airport by the Emirates Airline;

- The cost of passing one traveler between an origin and hub candidate and between a hub candidate and destination by the follower airlines;

Table 7. Origins and destinations.

\begin{tabular}{lcccccc}
\hline \multirow{2}{*}{ Origin } & Label & $i_{1}$ & $i_{2}$ & $i_{3}$ & $i_{4}$ & $i_{5}$ \\
& Airport & Hamburg & London & Stockholm & Paris & Rome \\
& & & & & & \\
\multirow{2}{*}{ Destination } & Label & $j_{1}$ & $j_{2}$ & $j_{3}$ & $j_{4}$ & $j_{5}$ \\
& Airport & Beijing & Bangkok & Kuala Lumpur & Delhi & Karachi \\
\hline
\end{tabular}

Table 8. Hub candidates for the follower airlines.

\begin{tabular}{lcccccccc}
\hline Label & $k_{1}$ & $k_{2}$ & $k_{3}$ & $k_{4}$ & $k_{5}$ & $k_{6}$ & $k_{7}$ & $k_{8}$ \\
Airport & Imam Khomeini & Mashhad & Tabriz & Isfahan & Shiraz & Bandar Abbas & Yazd & Zahedan \\
\hline
\end{tabular}

Table 9. Service quality, capacity, and the minimum number of passing travelers to consider an airport as a hub.

\begin{tabular}{lccccccccc}
\hline Airport & $\boldsymbol{k}_{\mathbf{1}}$ & $\boldsymbol{k}_{\mathbf{2}}$ & $\boldsymbol{k}_{\mathbf{3}}$ & $\boldsymbol{k}_{\mathbf{4}}$ & $\boldsymbol{k}_{\mathbf{5}}$ & $\boldsymbol{k}_{\mathbf{6}}$ & $\boldsymbol{k}_{\mathbf{7}}$ & $\boldsymbol{k}_{\mathbf{8}}$ & Dubai $^{\mathrm{a}}$ \\
\hline Service quality (*) & 3 & 3 & 3 & 3 & 3 & 1 & 1 & 1 & 4 \\
Capacity & 125,136 & 110,469 & 33,721 & 57,813 & 61,018 & 34,009 & 21,111 & 18,989 & - \\
Minimum number & 2,700 & 2,400 & 700 & 1,300 & 1,400 & 700 & 500 & 400 & - \\
\hline
\end{tabular}

a: Currently, Dubai international airport is the only hub of the Emirates airline. 
Table 10. Number of travelers.

\begin{tabular}{cccccc}
\hline $\begin{array}{c}\text { Number of } \\
\text { travelers }\end{array}$ & $\boldsymbol{j}_{\mathbf{1}}$ & $\boldsymbol{j}_{\mathbf{2}}$ & $\boldsymbol{j}_{\mathbf{3}}$ & $\boldsymbol{j}_{\mathbf{4}}$ & $\boldsymbol{j}_{\mathbf{5}}$ \\
\hline$i_{1}$ & 4020 & 3350 & 1340 & 4020 & 4020 \\
$i_{2}$ & 4020 & 2680 & 1340 & 4020 & 3350 \\
$i_{3}$ & 4020 & 4020 & 2010 & 4020 & 3350 \\
$i_{4}$ & 2010 & 2010 & 670 & 2010 & 2010 \\
$i_{5}$ & 4020 & 4020 & 1340 & 4020 & 4020 \\
\hline
\end{tabular}

- The time of passing travelers between an origin and hub candidate and between a hub candidate and destination by the follower airlines.

Furthermore, according to the information provided by Iran Airports and Air Navigation Company, it is assumed that the average travel time delay for the transfer of travelers in the airport $k$ of a follower airline is 60 minutes.

\subsection{Implementation of the uncertainty model}

Based on the abovementioned information, we implement a robust model and chance-constrained programming as follows.

\subsubsection{Implementation of the robust model}

We implement a robust model in a situation where all parameters $w_{i j}$ and $\Gamma_{k}$ are uncertain. By uncertainty of all parameters $w_{i j}$, we mean that:

$$
\begin{aligned}
& \Gamma_{i j}^{\text {const }}=1, \\
& \forall i \in I, \quad j \in J, \quad \text { const } \in\{1,2, \cdots, 7\} .
\end{aligned}
$$

Also, we suppose that:

$$
\widehat{w}_{i j}=0.1 * w_{i j} \quad \forall i \in I, \quad j \in J
$$

By using the GAMS software and through the Baron Solving method, it can be shown that the optimal value of the objective function for $\beta_{1}=0.8$ and $\gamma_{1}=0.9$ is $Z^{*}=\$ 702,464$, whereas the optimal value in the Marianov et al. [7] model is $Z^{*}=\$ 670,263$. Therefore, it can be concluded that the location of a hub in the present paper leads to a significant increase in the income of the follower airlines.

Table 11 shows the share of each hub of the follower airlines from the leader airline travelers.

According to Table 11, Imam Khomeini and Mashhad airports with 499 and 258 travelers have the largest international traffic among Iranian airports, respectively.

Given the results, it is clear that the Iranian airlines account for $2 \%$ of the travelers of the Emirates Airline (i.e., 1510 travelers).

Figure 1(a) and (b) show the path of passing travelers through hubs of the follower.
Table 11. Number of travelers passing the follower airports.

\begin{tabular}{cccccc}
\hline $\begin{array}{c}\text { Number of } \\
\text { travelers } \\
\text { (airport) }\end{array}$ & $\boldsymbol{j}_{\mathbf{1}}$ & $\boldsymbol{j}_{\mathbf{2}}$ & $\boldsymbol{j}_{\mathbf{3}}$ & $\boldsymbol{j}_{\mathbf{4}}$ & $\boldsymbol{j}_{\mathbf{5}}$ \\
\hline$i_{1}$ & $38\left(k_{2}\right)$ & $32\left(k_{1}\right)$ & $34\left(k_{8}\right)$ & $38\left(k_{1}\right)$ & $81\left(k_{1}\right)$ \\
& $43\left(k_{7}\right)$ & $36\left(k_{5}\right)$ & & & \\
& & & & & \\
$i_{2}$ & $24\left(k_{2}\right)$ & $25\left(k_{1}\right)$ & $13\left(k_{7}\right)$ & $38\left(k_{4}\right)$ & $36\left(k_{1}\right)$ \\
& $57\left(k_{5}\right)$ & $29\left(k_{2}\right)$ & $14\left(k_{4}\right)$ & $43\left(k_{8}\right)$ & $32\left(k_{2}\right)$ \\
& & & & & \\
$i_{3}$ & $43\left(k_{5}\right)$ & $38\left(k_{2}\right)$ & $19\left(k_{2}\right)$ & $38\left(k_{1}\right)$ & $47\left(k_{1}\right)$ \\
& $38\left(k_{1}\right)$ & $43\left(k_{6}\right)$ & $21\left(k_{6}\right)$ & $43\left(k_{7}\right)$ & \\
& & & & & \\
$i_{4}$ & $28\left(k_{5}\right)$ & $19\left(k_{1}\right)$ & $7\left(k_{6}\right)$ & $19\left(k_{4}\right)$ & $21\left(k_{1}\right)$ \\
& & $21\left(k_{6}\right)$ & & $21\left(k_{7}\right)$ & $19\left(k_{2}\right)$ \\
& $31\left(k_{2}\right)$ & & & & \\
& $27\left(k_{5}\right)$ & $38\left(k_{1}\right)$ & $13\left(k_{7}\right)$ & $43\left(k_{1}\right)$ & $43\left(k_{1}\right)$ \\
$i_{5}$ & $43\left(k_{8}\right)$ & $14\left(k_{6}\right)$ & $38\left(k_{8}\right)$ & $38\left(k_{2}\right)$ \\
& & & & &
\end{tabular}

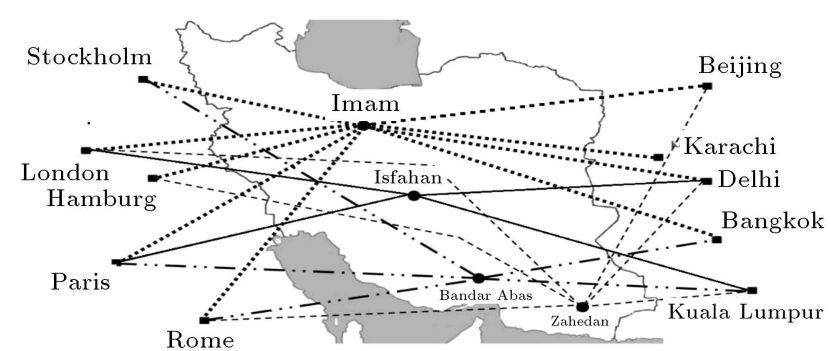

- Flow from Isfahan
.... Flow from Imam
$\ldots-$ Flow from Bandar Abas
-.-- Flow from Zahedan

(a)

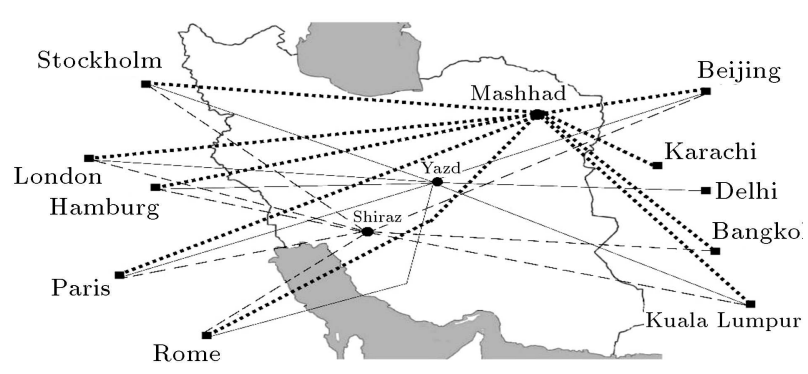

- Flow from Yazd

.... Flow from Mashhad

-.-- Flow from Shiraz

(b)

Figure 1. Hub-and-spoke network of the follower airlines (uncertainty mode).

\subsubsection{Implementation of the chance-constrained programming}

First, we show that the random variable $W_{i j}$ has a normal distribution so that the distribution functions of "P-value" and "AD" can be calculated using the Mini tab software. These values are given in Table 12 . 
Table 12. Distribution functions.

\begin{tabular}{clcc}
\hline Row & \multicolumn{1}{c}{ Distribution } & AD & $\boldsymbol{P}$-value \\
\hline 1 & Normal & 1.765 & $<0.005$ \\
2 & Logistic & 1.653 & $<0.005$ \\
3 & Box-cox transformation & 2.619 & $<0.005$ \\
4 & Gamma & 4.566 & $<0.005$ \\
5 & Log logistic & 4.69 & $<0.005$ \\
6 & Log normal & 4.877 & $<0.005$ \\
7 & Exponential & 9.495 & $<0.003$ \\
\hline
\end{tabular}

Table 13. Average travel demand.

\begin{tabular}{cccccc}
\hline $\begin{array}{c}\text { Number of } \\
\text { travelers }\end{array}$ & $\boldsymbol{j}_{\mathbf{1}}$ & $\boldsymbol{j}_{\mathbf{2}}$ & $\boldsymbol{j}_{\mathbf{3}}$ & $\boldsymbol{j}_{\boldsymbol{4}}$ & $\boldsymbol{j}_{\mathbf{5}}$ \\
\hline$i_{1}$ & 3618 & 3015 & 1206 & 3618 & 3618 \\
$i_{2}$ & 3618 & 2412 & 1206 & 3618 & 3015 \\
$i_{3}$ & 3618 & 3618 & 1809 & 3618 & 3015 \\
$i_{4}$ & 1809 & 1809 & 1206 & 1809 & 1809 \\
$i_{5}$ & 3618 & 3618 & 1206 & 3618 & 3618 \\
\hline
\end{tabular}

Table 14. Travel standard deviation.

\begin{tabular}{cccccc}
\hline $\begin{array}{c}\text { Number of } \\
\text { travelers }\end{array}$ & $\boldsymbol{j}_{\boldsymbol{1}}$ & $\boldsymbol{j}_{\boldsymbol{2}}$ & $\boldsymbol{j}_{\mathbf{3}}$ & $\boldsymbol{j}_{\boldsymbol{4}}$ & $\boldsymbol{j}_{\mathbf{5}}$ \\
\hline$i_{1}$ & 21 & 19 & 12 & 20 & 20 \\
$i_{2}$ & 20 & 17 & 14 & 20 & 19 \\
$i_{3}$ & 19 & 20 & 15 & 20 & 19 \\
$i_{4}$ & 15 & 17 & 11 & 16 & 14 \\
$i_{5}$ & 20 & 19 & 13 & 20 & 20 \\
\hline
\end{tabular}

Given the values of "AD" and "P-value" in Table 12, it is concluded that the best distribution for displaying the parameters is the normal distribution. Therefore, taking into account the matrices of $E\left(\tilde{W}_{i j}\right)$ and $\sqrt{\operatorname{Var}\left(\tilde{W}_{i j}\right)}$ through Tables 13 and 14 and placing them in Constraints (38) to (44), the optimal value of the objective function with $Z_{0.95}=1.645$ is equal to $Z^{*}=\$ 695,082$.

Therefore, it can be concluded that if random constraints are possible with a probability of $95 \%$, the value of the objective function will be $\$ 695,082$.

Table 15 shows the share of each hub of the follower airlines from the leader airline travelers.

Since it is not possible to determine with certainty which chance-constrained programming and robust optimization methods provide an accurate approximation of the optimal problem [34], considering that the value of the objective function in the robust optimization method is greater than that in the random constrained programming, in the following, the result of the robust optimization method is considered as the basis for decision-making and analysis of the results.
Table 15. Number of travelers passing the follower airports.

\begin{tabular}{|c|c|c|c|c|c|}
\hline $\begin{array}{c}\text { Number of } \\
\text { travelers } \\
\text { (airport) }\end{array}$ & $j_{1}$ & $j_{2}$ & $j_{3}$ & $j_{4}$ & $j_{5}$ \\
\hline$i_{1}$ & $\begin{array}{l}38\left(k_{2}\right) \\
43\left(k_{7}\right)\end{array}$ & $\begin{array}{l}32\left(k_{1}\right) \\
36\left(k_{5}\right)\end{array}$ & $14\left(k_{8}\right)$ & $\begin{array}{l}38\left(k_{1}\right) \\
43\left(k_{7}\right)\end{array}$ & $80\left(k_{1}\right)$ \\
\hline$i_{2}$ & $\begin{array}{l}24\left(k_{2}\right) \\
57\left(k_{5}\right)\end{array}$ & $\begin{array}{l}25\left(k_{1}\right) \\
29\left(k_{2}\right)\end{array}$ & $\begin{array}{l}12\left(k_{7}\right) \\
14\left(k_{4}\right)\end{array}$ & $\begin{array}{l}38\left(k_{4}\right) \\
43\left(k_{8}\right)\end{array}$ & $\begin{array}{l}35\left(k_{1}\right) \\
31\left(k_{2}\right)\end{array}$ \\
\hline$i_{3}$ & $\begin{array}{l}43\left(k_{5}\right) \\
38\left(k_{1}\right)\end{array}$ & $\begin{array}{l}38\left(k_{2}\right) \\
43\left(k_{6}\right)\end{array}$ & $\begin{array}{l}19\left(k_{2}\right) \\
21\left(k_{6}\right)\end{array}$ & $\begin{array}{l}38\left(k_{1}\right) \\
43\left(k_{7}\right)\end{array}$ & $67\left(k_{1}\right)$ \\
\hline$i_{4}$ & $28\left(k_{5}\right)$ & $\begin{array}{l}19\left(k_{1}\right) \\
21\left(k_{6}\right)\end{array}$ & $7\left(k_{6}\right)$ & $\begin{array}{l}19\left(k_{4}\right) \\
21\left(k_{7}\right)\end{array}$ & $\begin{array}{l}21\left(k_{1}\right) \\
19\left(k_{2}\right)\end{array}$ \\
\hline$i_{5}$ & $\begin{array}{l}31\left(k_{2}\right) \\
27\left(k_{5}\right) \\
43\left(k_{8}\right)\end{array}$ & $\begin{array}{l}38\left(k_{1}\right) \\
43\left(k_{6}\right)\end{array}$ & $\begin{array}{l}13\left(k_{7}\right) \\
14\left(k_{6}\right)\end{array}$ & $\begin{array}{l}43\left(k_{1}\right) \\
38\left(k_{8}\right)\end{array}$ & $\begin{array}{l}43\left(k_{1}\right) \\
38\left(k_{2}\right)\end{array}$ \\
\hline
\end{tabular}

\subsubsection{Comparison of costs and travel times}

Based on the information gathered about the Emirates airline, it can be stated that the cost of passing the existing travelers is $\$ 1,252,088$. Therefore, we can conclude that the alliance of the Iranian airlines and using the competitive edge they gain not only leads to an increase in their market share by $\$ 702,464$, but also decreases the ticket costs for travelers by $\$ 549,624$. The value of 549,624 is achieved by the cost of the Emirates airline $(1,252,088)$ minus the cost of alliance among the Iranian airlines $(702,464)$ for passing 1,510 travelers. If $\beta_{1}=0.8$ and $\gamma_{1}=0.9$, on average, there will be about $\$ 364$ reduction in ticket price per traveler. Furthermore, it can be said that the time needed to transport all the existing travelers (in Table 11) by the Emirates airline is about 21,000 h, while this time for the alliance of the Iranian airlines is about 19,516. When we consider the alliance of the Iranian airlines and the hubs under their control, travel time per traveler decreases by about 59 minutes on average. This value is gained by the time of the Emirates airline $(21,000 \mathrm{~h})$ minus the time of the alliance among the Iranian airlines $(19,516 \mathrm{~h})$ for passing 1,510 travelers.

\subsubsection{Sensitivity analysis}

To assess the impact of the quality and safety of the follower airlines and the number of hubs under their control and examine changes in the discount factor $\left(\beta_{1}\right.$, $\gamma_{1}$ ) for the value of $z$, we implement the model with different values of $\beta_{1}, \gamma_{1}, U_{f}, U_{l}, S_{f}, S_{l}$ and $|K|$. The results are presented in Tables 12 to 14 .

Table 16 shows the impact of discount factors $\beta_{1}$ 
Table 16. Sensitivity analysis of discount factors.

\begin{tabular}{cccc}
\hline Discount factors & $\boldsymbol{\beta}_{1}=1, \boldsymbol{\gamma}_{1}=1$ & $\boldsymbol{\beta}_{1}=0, \boldsymbol{\gamma}_{1}=1$ & $\boldsymbol{\beta}_{1}=0.9, \boldsymbol{\gamma}_{1}=0.9$ \\
\hline$z$ & 822585 & 746016 & 740397 \\
\hline
\end{tabular}

Table 17. Sensitivity analysis of the number of airports.

\begin{tabular}{ccccc}
\hline $\boldsymbol{K} \mid$ & $\mathbf{4}$ & $\mathbf{5}$ & $\mathbf{6}$ & $\mathbf{7}$ \\
\hline$z$ & 665843 & 688690 & 693449 & 702464 \\
\hline
\end{tabular}

Table 18. Sensitivity analysis of quality and safety.

\begin{tabular}{cccc}
\hline$\frac{U_{f}}{U_{l}}, \frac{S_{f}}{S_{l}}$ & $\mathbf{0 . 5}, \mathbf{0 . 2}$ & $\mathbf{0 . 4}, \mathbf{0 . 3}$ & $\mathbf{0 . 5}, \mathbf{0 . 3}$ \\
\hline$z$ & 878080 & 1053696 & 1317120 \\
\hline
\end{tabular}

and $\gamma_{1}$ for the follower airlines on the value of the objective function.

Based on the last column of Table 16, it can be stated that a $0.1 \%$ increase in the discount factor $\beta_{1}$ leads to an increase in the value of $z$ by $\$ 37,933$. On the other hand, based on the second column of Table 16, a $0.1 \%$ increase in the discount factor $\gamma_{1}$ results in an increase in the value of $z$ by $\$ 43,552$. Therefore, we conclude that the discount factor $\gamma_{1}$ has a higher impact on profitability than the discount factor $\beta_{1}$. Also, based on the first column of Table 16 and the cost of passing travelers by the Emirates airline $(\$ 1,252,088)$, it can be concluded that a decrease in the ticket prices for travelers $(\$ 429,503)$ is possible when the follower airlines do not use the discount factor in passing the travelers.

Table 17 indicates the impact of the number of airports controlled by the follower airlines on the value of the objective function.

As shown in Table 17, an increase in the number of hub airports of the follower airlines leads to an increase in the value of the objective function. By simple calculations, it can be shown that adding one airport to the airports controlled by the follower airlines leads to a $1 \%$ increase in their gained revenue.

Table 18 shows the impact of the quality and safety of the follower airlines on the value of the objective function.

The first column of Table 18 shows that a $10 \%$ increase in the quality of the follower airlines leads to a $25 \%$ increase in the value of the objective function, while a $10 \%$ increase in the safety of the follower airlines (second column of Table 18) leads to a $50 \%$ increase in revenue of the follower airlines. Therefore, it can be concluded that the safety of the airlines is more effective in traveler attraction and revenue increase. The third column of Table 18 shows that a $10 \%$ increase in each of the parameters of quality and safety for the follower airlines leads to a nearly $88 \%$ increase in the value of the objective function.
Table 19. The impact of the uncertain parameters of travel demand.

\begin{tabular}{ccc}
\hline $\boldsymbol{\Gamma}_{\boldsymbol{i j}}^{\text {const }}$ & $\widehat{\boldsymbol{w}}_{\boldsymbol{i j}}$ & $\boldsymbol{z}^{*}$ \\
\hline \multirow{2}{*}{10} & $0.1\left(w_{i j}\right)$ & 658474 \\
& $0.2\left(w_{i j}\right)$ & 632802 \\
& $0.3\left(w_{i j}\right)$ & 602738 \\
& & \\
\multirow{2}{*}{15} & $0.1\left(w_{i j}\right)$ & 642389 \\
& $0.2\left(w_{i j}\right)$ & 600211 \\
& $0.3\left(w_{i j}\right)$ & 553851 \\
& & \\
20 & $0.1\left(w_{i j}\right)$ & 634977 \\
& $0.2\left(w_{i j}\right)$ & 585367 \\
& $0.3\left(w_{i j}\right)$ & 531586 \\
& & \\
& $0.1\left(w_{i j}\right)$ & 619656 \\
& $0.2\left(w_{i j}\right)$ & 554344 \\
& $0.3\left(w_{i j}\right)$ & 485050 \\
\hline
\end{tabular}

Table 20. The impact of the number of uncertain parameters (travel demand).

\begin{tabular}{cc}
\hline $\begin{array}{c}\text { Number of } \\
\text { uncertain parameters }\end{array}$ & $\begin{array}{c}\text { Percentage of change in } \\
\text { the objective function }\end{array}$ \\
\hline 10 & 6 \\
15 & 9 \\
20 & 10 \\
25 & 13 \\
\hline
\end{tabular}

To examine the impact of the number of uncertain parameters, we consider Table 19.

According to Table 19, the higher the number of uncertain parameters in the model, the worse the value of the objective function will be. For example, when all the $33 w_{i j}$ parameters are uncertain with the following deviation value:

$$
\widehat{w}_{i j}=0.3 * w_{i j}
$$

the value of the objective function is equal to $\$ 485050$, which is $\$ 217414$ lower than the optimal value of a certain model (\$702464).

Also, it is clear that as the number of uncertain parameters increases, the value of the objective function decreases accordingly and becomes more realistic. Table 20 shows the change percentage in the value of the objective function in a robust model in comparison 
with a certain model in various modes (the number of travelers has a $10 \%$ deviation from the real value).

\section{Conclusion}

In this paper, in order to organize the travelers and determine the exact location of hubs, we developed the model of Marianov et al. [7] by defining a new type of capture sets under uncertainty in which the follower airlines attracted a percentage of the leader airline travelers. We divided the nominated airports for the follower airline hubs into six independent categories by comparing the parameters of travel time, travel cost, and service quality of the airports of the follower and leader airlines. By employing a multivariate Lagrange interpolation function, we determined the degrees of importance for the time and cost of travel from the travelers' perspective. By using the degrees of importance for the time and cost of travel as well as comparing the parameters of quality, safety, and delays between the leader and follower airlines, we allocated travelers to the determined six sets. Based on the seasonal demand of the local travelers, we considered the travel demand of hubs as an uncertain parameter. To identify the deterministic equivalent forms for these categories of hub location models, the robust optimization method and chance-constrained programming were employed. The results showed that the income of the follower airlines would experience a considerable growth compared to the Marianov et al. [7] model and could absorb nearly $2 \%$ of the travelers of the leader airline due to lower travel costs and times. By examining the change in the parameters of the model, we observed that improvement in the quality and safety of the follower airlines and increase in the number of hubs under their control would have a positive impact on their gained revenue.

\section{References}

1. Rodríguez-Martín, I. and Salazar-González, J. "Solving a capacitated hub location problem", Eur. J. Oper. Res., 184(2), pp. 468-479 (2008).

2. Campbell, J.F. "Hub location for time definite transportation", Comput. Oper. Res., 36(12), pp. 31073116 (2009).

3. Yaman, H., Kara, B.Y., and Tansel, B.Ç. "The latest arrival hub location problem for cargo delivery systems with stopovers", Transport. Res. B-Meth., 41(8), pp. 906-919 (2007).

4. Van Belle, J., Valckenaers, P., and Cattrysse, D. "Cross-docking: State of the art", Omega., 40(6), pp. 827-846 (2012).

5. Campbell, J.F. "Integer programming formulations of discrete hub location problems", Eur. J. Oper. Res., 72(2), pp. 387-405 (1994).
6. Hakimi, S.L. "Optimum distribution of switching centers in a communication network and some related graph theoretic problems", Oper. Res., 13(3), pp. 462475 (1965).

7. Marianov, V., Serra, D., and ReVelle, C. "Location of hubs in a competitive environment", Eur. J. Oper. Res., 114(2), pp. 363-371 (1999).

8. Wagner, B. "A note on "location of hubs in a competitive environment", Eur. J. Oper. Res., 184(1), pp. 57-62 (2008).

9. Soyster, A.L. "Convex programming with set-inclusive constraints and applications to inexact linear programming”, Oper. Res., 21(5), pp. 1154-1157 (1973).

10. Ben-Tal, A. and Nemirovski, A. "Robust solutions of uncertain linear programs", Oper. Res. Let., 25(1), pp. 1-13 (1999).

11. Bertsimas, D. and Sim, M. "The price of robustness", Oper. Res., 52(1), pp. 35-53 (2004).

12. Nourzadeh, F., Ebrahimnejad, S., Khalili-Damghani, K., et al. "Forecasting the international air passengers of Iran using an artificial neural network", Int. J. Ind. Syst. Eng., 34(4), pp. 562-581 (2020).

13. Sasaki, M. and Fukushima, M. "Stackelberg hub location problem", J. Oper. Res. Soc. JPN., 44(4), pp. 390-402 (2001).

14. Sasaki, M. "Hub network design model in a competitive environment with flow threshold", J. Oper. Res. Soc. JPN., 48(2), pp. 158-171 (2005).

15. Sasaki, M., Campbell, J.F., Krishnamoorthy, M., et al. "Designing hub and spoke transportation systems for a competitive environment", In Int. Con. Ind. Eng. Syst. Manage., pp. 13-15 (2009).

16. Eiselt, H.A. and Marianov, V. "A conditional p-hub location problem with attraction functions", Comput. Oper. Res., 36(12), pp. 3128-3135 (2009).

17. Lin, M.H. "Strategic airline alliances and endogenous Stackelberg equilibria", Transport. Res. E- Log., 40(5), pp. 357-384 (2004).

18. Zou, L. and Chen, X. "The effect of code-sharing alliances on airline profitability", J. Air. Transp. Manag., 58, pp. 50-57 (2017).

19. Yimga, J.O. "Airline code-sharing and its effects on on-time performance", J. Air. Transp. Manag., 58, pp. 76-90 (2017).

20. Adibi, A. and Razmi. J. "2-stage stochastic programming approach for hub location problem under uncertainty: A case study of air network of Iran", $J$. Air. Transp. Manag., 47, pp. 172-178 (2015).

21. Boukani, F.H., Moghaddam, B.F., and Pishvaee, M.S. "Robust optimization approach to capacitated single and multiple allocation hub location problems", Comput. Appl. Math., 35(1), pp. 45-60 (2016).

22. Tikani, H., Honarvar, M., and Mehrjerdi, Y.Z. "Developing an integrated hub location and revenue management model considering multi-classes of customers in the airline industry", Comput. Appl. Math., 37(3), pp. 3334-3364 (2018). 
23. Nikoofal, M.E. and Sadjadi, S.J. "A robust optimization model for p-median problem with uncertain edge lengths", Int. J. Adv. Manuf. Tech., 50(1-4), pp. 391397 (2010).

24. Ghaffari-Nasab, N., Ghazanfari, M., and Teimoury, E. "Robust optimization approach to the design of huband-spoke networks", Int. J. Adv. Manuf. Tech., 76(58), pp. 1091-1110 (2015).

25. Zetina, C.A., Contreras, I., Cordeau, J.F., et al. "Robust uncapacitated hub location", Transport. Res. B-Meth., 106, pp. 393-410 (2017).

26. Charnes, A., Cooper, W.W., and Symonds, G.H. "Cost horizons and certainty equivalents: an approach to stochastic programming of heating oil", Manag. Sci., 4(3), pp. 235-263 (1958).

27. Gao, Y. and Qin, Z. "A chance constrained programming approach for uncertain p-hub center location problem", Comput. Ind. Eng., 102, pp. 10-20 (2016).

28. Farina, M., Giulioni, L., and Scattolini, R. "Stochastic linear model predictive control with chance constraints-a review", J. Process. Contr., 44(1), pp. 53-67 (2016).

29. Tan, X., Gong, Z., Chiclana, F., et al. "Consensus modeling with cost chance constraint under uncertainty opinions", Appl. Soft. Comput., 67(1), pp. 721$727(2017)$

30. Elci, O., Noyan, N., and Bulbul, K. "Chanceconstrained stochastic programming under variable reliability levels with an application to humanitarian relief network design", Comput. Oper. Res., 96(1), pp. 91-107 (2018).

31. Saniee, K. "A simple expression for multivariate Lagrange interpolation", SIAM. Undergrad. Res. Online., 1(1), pp. 1-9 (2008).

32. Charnes, A. and Cooper, W.W. "Chance-constrained programming", Manag. Sci., 6(1), pp. 73-79 (1959).

33. Di Bucchianico, A., Coefficient of Determination (R2), John Wiley \& Sons (2008).

34. Houda, M. "Comparison of approximations in stochastic and robust optimization programs", In Prague Stochastics, pp. 418-425 (2006).

\section{Biographies}

Farzin Nourzadeh obtained his BSc degree in Pure Mathematics from Urmia University, Urmia, Iran, in 2007 and MSc degree in Applied Mathematics with speciality in Operations Research from Kurdistan University, Sanandaj, Iran, in 2009. Furthermore, he obtained his $\mathrm{PhD}$ degree in Industrial Engineering from the Islamic Azad University, South Tehran Branch, Tehran, Iran, in 2019. His research interests include hub location, optimization modelling, DEA, game theory, mathematical modelling, and applied operations research.

Sadoullah Ebrahimnejad is an Associate Professor of Industrial Engineering at Karaj Islamic Azad University (KIAU). He holds a BSc in Industrial Engineering from Iran University of Science and Technology, MSc from Amirkabir University of Technology, and PhD from the Science and Research Branch of the Islamic Azad University (Tehran SRBIAU). His research interests are fuzzy MADM/MODM, SCM networks, operation management, optimization models, risk management, and multi-criteria network optimization. He has published more than 80 papers in reputable academic journals and conferences.

Kaveh Khalili-Damghani is currently an Associate Professor of Industrial Engineering at Islamic Azad University, South Tehran Branch, Tehran, Iran. He obtained his first $\mathrm{PhD}$ degree in Industrial Engineering with speciality in Operations Research from the Islamic Azad University, Science and Research Branch, Tehran, Iran, in 2008 and his second $\mathrm{PhD}$ degree in Industrial Management with speciality in Operations and Production Management from Allameh Tabataba'i University, Tehran, Iran, in 2012. His MSc degree was in Industrial Engineering with speciality in Operations Research from Islamic Azad University, South Tehran Branch, Tehran, Iran, in 2005 and his BSc was in Industrial Engineering with speciality in Industrial Production from the same univerdity in 2003. His current research interests are mathematical modelling and applied operations research, combinatorial optimization, soft computing, operations and production management in supply chains, and data envelopment analysis for performance assessment.

Ashkan Hafezalkotob is currently an Associate Professor of Industrial Engineering at Islamic Azad University, South Tehran Branch, Tehran, Iran. He obtained his MSc and PhD degrees in Industrial Engineering with speciality in Social and Economic Systems Engineering from the Iran University of Science and Technology, Tehran, Iran, in 2007 and 2012, respectively. Also, he received a BSc degree in Industrial Engineering with speciality in Production Engineering from Islamic Azad University, South Tehran Branch, Tehran, Iran, in 2004. His current research interests are applied game theory, multi-criteria decision making, competition and cooperation, logistics, energy economics, operations research, and metaheuristic methods. 